\title{
A controlled study of sensory tics in Gilles de la Tourette syndrome and obsessive-compulsive disorder using a structured interview
}

\author{
Kit-Yun Chee, Perminder Sachdev
}

\begin{abstract}
Objective-To determine the prevalence and characteristics of sensory tics in the Gilles de la Tourette syndrome (GTS), and a matched population of patients with obsessive-compulsive disorder (OCD) using a structured assessment.

Methods-50 subjects each of GTS, OCD, and healthy controls were studied to determine the prevalence and phenomenology of sensory tics, and diagnose tic disorders, OCD, and affective disorders according to DSM-III-R criteria. The severity of tics and obsessive-compulsive symptoms were quantified using the Tourette syndrome global scale (TSGS) and Yale-Brown obsessive-compulsive scale (Y-BOCS) respectively.

Results-The GTS group (28\%) had significantly greater life-time prevalence of sensory tics than the OCD $(10 \%)$ and healthy $(8 \%)$ groups $(P<0.05)$. The sensory tics in both the GTS and OCD groups were predominantly located in rostral anatomical sites. Multiple sensory tics occurred in some patients with GTS or OCD, but not in healthy subjects. Within the OCD group, those who had sensory tics had significantly higher TSGS scores $(P<0.0001)$, and a higher prevalence of GTS $(P<0.005)$.

Conclusions-Sensory tics seem to be a common and distinctive feature of GTS and that subpopulation of patients with OCD predisposed to tic disorders. Neurophysiologically, a possible explanation for sensory tics is that they represent the subjectively experienced component of neural dysfunction below the threshold for motor and vocal tic production.
\end{abstract}

Table 1 Nosology and definitions of sensory tics as described in the published literature

\begin{tabular}{|c|c|c|c|}
\hline Author & Nosology & $\begin{array}{l}\text { Symptoms } \\
\text { included } \\
\text { in definition }\end{array}$ & $\begin{array}{l}\text { Motor or vocal } \\
\text { response to } \\
\text { sensation required }\end{array}$ \\
\hline Bliss et al $1983^{\circ}$ & $\begin{array}{l}\text { Sensory } \\
\text { experiences }\end{array}$ & $\begin{array}{l}\text { Urge } \\
\text { Somatic sensations }\end{array}$ & No \\
\hline Shapiro et al $1988^{10}$ & Sensory tic & Somatic sensations & Yes \\
\hline Kurlan et al $1989^{11}$ & Sensory tic & $\begin{array}{l}\text { Somatic sensations } \\
\text { Psychological experiences }\end{array}$ & Yes \\
\hline Cohen and Leckman $1992^{12}$ & Sensory phenomena & $\begin{array}{l}\text { Urge } \\
\text { Somatic sensations } \\
\text { Heightened sensitivity } \\
\text { Impulsivity }\end{array}$ & No \\
\hline $\begin{array}{l}\text { Leckman et al } 1993^{13} \\
\text { Present study }\end{array}$ & Premonitory urge & $\begin{array}{l}\text { Urge } \\
\text { Somatic sensations }\end{array}$ & $\begin{array}{l}\text { Yes } \\
\text { No }\end{array}$ \\
\hline
\end{tabular}

Keywords: Gilles de la Tourette syndrome; obsessive compulsive disorder; structured interview; sensory tics

$(\mathfrak{F}$ Neurol Neurosurg Psychiatry 1997;62:188-192)

Introduction

The Gilles de la Tourette syndrome (GTS) is a neuropsychiatric disorder characterised by the presence of multiple motor tics and at least one vocal tic. ${ }^{1}$ It is now widely recognised that GTS is more complex than the above definition implies, and there is evidence that obsessive-compulsive disorder (OCD) is an important comorbid condition ${ }^{2-7}$ that may be genetically linked to GTS. ${ }^{8}$

Bliss et $a l^{9}$ recently kindled interest in an area which had hitherto received little attention, when they described Bliss's own "sensory" tics in the context of a 62 year history of GTS. Since then, four systematic studies of this symptom have been published. ${ }^{10-13}$ Of these, only two used direct interviews, ${ }^{1012}$ and none of the studies was controlled. The inclusion of a healthy control population is important because the phenomena described are subjective and therefore difficult to characterise as pathological with certainty. In addition, as far as we are aware, the presence of sensory tics in OCD has not been examined, and has the potential of increasing our understanding of the complex links between GTS and OCD.

An examination of the medical literature discloses considerable variation in the nosology and definition of these sensory experiences. Table 1 summarises this. We defined sensory tics as somatic sensations which were: (a) transient and recurrent, (b) experienced at or close to the skin, (c) readily localisable by the patient to a particular part of the body, and recognised as stereotyped and unusual, (d) experienced with or without an associated motor or vocal response, and (e) experienced in the absence of obvious physical pathology. Specifically, we excluded "urges" from sensory tics because: (1) An "urge" is a drive that often precedes a behavioural response (in this case, a tic), although the behaviour may be consciously suppressed. It is therefore a cognitive rather than a sensory experience. (2) Even when patients describe an urge in a body part (rather than in the mind), they do not localise it close to the skin, and do not equate it with a somatic sensation. (3) Most patients with GTS report that, at least some of the time, their tics are preceded by a conscious 
urge. Furthermore, we defined motor and vocal tics as repetitive, stereotyped movements, behaviours, or vocalisations, preceded at least sometimes by a conscious urge, performed as an end in itself and experienced as irresistible but suppressible.

\section{Methods}

We recruited 50 patients with GTS, who met DSM-III-R criteria, by contacting patients previously seen at the Neuropsychiatric Institute and advertising through the Tourette Syndrome Association of Australia. In addition, we recruited 50 patients with DSM-III-R diagnosis of OCD from three hospitals in Sydney, and from OCD support groups. Because it is possible for GTS and OCD to co-occur in a patient, we used the following guidelines in assigning a subject to a primary category of GTS or OCD: (1) the primary disorder was the one which had the most prominent symptomatology in the previous year, and whose symptoms (tics $v$ obsessions-compulsions) produced the greater distress or disability and had brought the patient to medical attention; (2) both investigators independently agreed on the primary diagnosis; and (3) an independent psychiatrist concurred with the assignment. All patients with GTS and OCD could be assigned on these guidelines without dispute. Fifty healthy controls, who were volunteers with no history of GTS, chronic motor tic disorder, or OCD, were recruited from personnel of the Eastern Sydney Area Health Service by advertisement. On detailed assessment, however, five otherwise healthy controls had had a lifetime of OCD and these were therefore excluded from the analyses. We excluded subjects with active psychoses, significant head injury, other neurological disorders, and drug or alcohol misuse. To improve the accuracy of reports elicited, we excluded subjects under the age of 10 and interviewed all subjects under the age of 16 in the presence of an adult informant. Informed consent was obtained from all participants, and when appropriate, a parent or guardian.

Subjects were interviewed using a modified Yale schedule for Tourette and other behavioural syndromes. ${ }^{8}$ This schedule yielded DSM-III-R diagnoses for GTS, chronic and transient tic disorders, OCD, major depression, and mania. The schedule was modified by the addition of questions on the presence of sensory tics, their characteristics, anatomical location, and the motor or vocal responses to these sensations (see appendix 1). We also added questions on the features used in defining motor and vocal tics as described above. We omitted questions on social, educational, and occupational history, factors which exacerbated or relieved tics, and questions used to derive conduct and personality disorder diagnoses (modified schedule available from the authors on request). Subjects were also rated on measures of severity of tics and obsessivecompulsive symptoms, using the Tourette syndrome global scale (TSGS) ${ }^{14}$ and the YaleBrown obsessive-compulsive scale (Y-BOCS) respectively. ${ }^{15} 16$
Table 2. Demographic and clinical features-a comparison of groups of patients with healthy controls

\begin{tabular}{|c|c|c|c|}
\hline & $\begin{array}{l}G T S \\
(n=50)\end{array}$ & $\begin{array}{l}O C D \\
(n=50)\end{array}$ & $\begin{array}{l}\text { Healthy } \\
(n=45)\end{array}$ \\
\hline $\begin{array}{l}\text { Age }(\text { mean }(S D))^{a} \\
\text { Sex } M / F^{b}\end{array}$ & $\begin{array}{l}20 \cdot 8(10 \cdot 8) \\
40 / 10\end{array}$ & $\begin{array}{l}31 \cdot 2(13 \cdot 3) \\
29 / 21\end{array}$ & $\begin{array}{l}20 \cdot 7(5 \cdot 3) \\
22 / 23\end{array}$ \\
\hline $\begin{array}{l}\text { TSGS score: } \\
\text { Mean } \\
\text { Median } \\
\text { Range }\end{array}$ & $\begin{array}{l}23 \cdot 0 \\
23 \cdot 0 \\
1 \cdot 5-56 \cdot 7\end{array}$ & $\begin{array}{l}1 \cdot 2 \\
0 \cdot 0 \\
0 \cdot 0-27 \cdot 8\end{array}$ & $\begin{array}{l}0.0 \\
0.0 \\
0.0\end{array}$ \\
\hline $\begin{array}{l}\text { Y-BOCS score: } \\
\text { Mean } \\
\text { Median } \\
\text { Range }\end{array}$ & $\begin{array}{l}5 \cdot 6 \\
0 \cdot 0 \\
0 \cdot 0-29 \cdot 0\end{array}$ & $\begin{array}{l}18 \cdot 2 \\
18 \cdot 0 \\
0 \cdot 0-34 \cdot 0\end{array}$ & $\begin{array}{l}0 \cdot 1 \\
0 \cdot 0 \\
0 \cdot 0-6 \cdot 0\end{array}$ \\
\hline
\end{tabular}

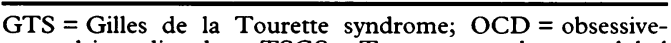
compulsive disorder; TSGS = Tourette syndrome global scale; Y-BOCS = Yale-Brown obsessive-compulsive scale. 'The OCD group was older than the healthy group $(t=4 \cdot 95$, $\mathrm{df}=93, \mathrm{P}<0.0001$ )

'There were more males in the GTS than the healthy group

$\left(\chi^{2}=9 \cdot 8, \mathrm{df}=1\right.$, OR $\left.4 \cdot 3, \mathrm{P}<0 \cdot 005\right)$.

'GTS $v$ healthy; Mann-Whitney $U=0, \mathrm{~W}=1035.0$,

$\mathrm{P}<0.0001$.

'OCD $v$ healthy; Mann-Whitney $U=877 \cdot 5, \mathrm{~W}=1912 \cdot 5$, $P<0.001$.

${ }^{\mathrm{d}} \mathrm{GTS} v$ healthy; Mann-Whitney $U=694 \cdot 0, \mathrm{~W}=1729 \cdot 0$

$\mathrm{P}<0.0001$.

${ }^{\mathrm{O} O C D} v$ healthy; Mann-Whitney $U=48.0, \mathrm{~W}=1083.0$,

$\mathrm{P}<0.0001$.

\section{Results}

Table 2 gives the demographic and clinical features of the three groups. The GTS group had significantly more males, and the OCD group was significantly older than the healthy group. The implications of these differences are discussed below. The number of subjects below the age of 16 in the GTS, OCD, and healthy groups were 20,7 , and 10 respectively. Both the GTS and OCD groups had higher TSGS and Y-BOCS scores than controls. A within group analysis was performed comparing hospital to support group ascertained subjects in the GTS and OCD groups according to age, sex ratio, severity of primary symptoms, and the prevalence of sensory tics. The only significant finding was that patients with OCD in hospital were older than those from support groups $(t=5.5, \mathrm{df}=48, \mathrm{P}<0.0001$, two tailed). The number of subjects from the two patient groups, GTS and OCD, respectively, who were on psychotropic medication in the three weeks before the study was as follows: 27 and two on antipsychotic drugs, three and 32 on antidepressant drugs, nine and none on clonidine, and none and nine on benzodiazepines. None of the healthy group was currently taking psychotropic medications.

The lifetime prevalences of sensory tics in the GTS, OCD, and healthy groups were $28 \%$ (14 patients), $10 \%$ (five patients), and $8.9 \%$ (four subjects) respectively. Patients with GTS were significantly more likely to experience sensory tics than either the OCD or healthy groups $\left(\chi^{2}=4 \cdot 2, \mathrm{df}=1\right.$, odds ratio $=3 \cdot 5, \mathrm{P}<$ 0.05 ; GTS $v$ normal group, $\chi^{2}=5 \cdot 5, \mathrm{df}=1$, odds ratio $=4.5, \mathrm{P}<0.05)$. The prevalence of sensory tics in OCD was not different from healthy controls. We also pooled the data from the subgroup of OCD probands with a chronic tic or GTS with the subgroup of GTS probands with OCD. The pooled group were then compared with the two residual groupsthat is, GTS without OCD, and OCD without 
Anatomical distribution of sensory tics. $T S=$ Tourette syndrome; $O C D=$ obsessive-compulsive disorder; healthy = control subjects.

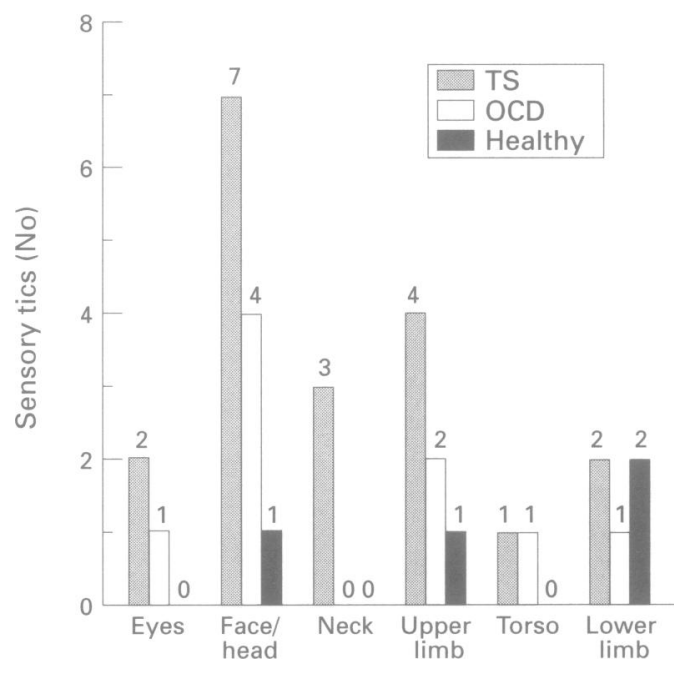

Anatomical locations

tic disorder - and to the healthy group. The pooled group had significantly more sensory tics than the residual OCD group $\left(\chi^{2}=12 \cdot 6\right.$, $\mathrm{df}=1, \mathrm{P}<0.05$, odds ratio $=5.9$ ) but was not different from the residual GTS group.

The figure summarises the anatomical locations of the sensory tics suggesting that patients with GTS and OCD had sensory tics primarily in rostral body regions. Table 3 gives a qualitative description of the sensory tics in some of the patients' own words. Various sensations were described, but they were usually distinctive to the individual patient with most patients being able to distinguish them from the "common itching and tingling" sensations experienced by most people at some time or other. An important property of the sensory tics was their stereotyped occurrence in the same body sites. In addition, patients could distinguish the sensory phenomena from the "urge" that often precedes a motor or vocal tic. Sensory tics were reported in more than one site by four patients with GTS and two with OCD, but no healthy controls.

Within the GTS group, we examined the motor and vocal responses after the 19 sensory tics. Seven $(36.8 \%)$ were not followed by any motor or vocal responses. Another seven $(36.8 \%)$ were followed by sudden and brief movements or vocalisations typical of simple

Table 3 Somatic sensations in sensory tics

\begin{tabular}{llll}
\hline Description & $\begin{array}{l}\text { GTS } \\
(n=50)\end{array}$ & $\begin{array}{l}\text { Group } \\
\text { OCD } \\
(n=50)\end{array}$ & $\begin{array}{l}\text { Healthy } \\
(n=45)\end{array}$ \\
\hline $\begin{array}{l}\text { Tingling/“crinkling"/ } \\
\text { electrical sensations }\end{array}$ & 5 & 3 & - \\
$\begin{array}{l}\text { Itch/tickle/“insect } \\
\text { crawling" }\end{array}$ & 5 & 1 & 1 \\
$\begin{array}{l}\text { Tightness/tension } \\
\text { Other: }\end{array}$ & 2 & 2 & - \\
$\begin{array}{l}\text { Numbness } \\
\text { "Someone close to }\end{array}$ & 1 & - & - \\
$\begin{array}{l}\text { my ear" } \\
\text { Acullness" }\end{array}$ & 1 & - & - \\
$\begin{array}{l}\text { "Une } \\
\text { ever experienced }\end{array}$ & - & 1 & - \\
\hline
\end{tabular}

Figures indicate number of patients with the symptoms. Some patients had multiple symptoms.

patients had multiple symptoms. compulsive disorder. tics - for example, sudden upward conjugate deviation of the eyes, brief opening of mouth, jerking of the arm, and coughing. Six (31.6\%) were followed by slower, more purposive movements such as rubbing, scratching, and touching the site of the sensory tic. The prevalence of sensory tics in the OCD and control groups was too low for meaningful comparison of response type.

Within each subject group, we compared the subgroup with sensory tics to those without. The most striking finding (table 4) was that the presence of sensory tics in patients with OCD was associated with an increased prevalence of GTS. It was also associated with a significantly increased score of motor and vocal tic severity as measured on the TSGS. Otherwise, age, sex ratio, severity of tics and obsessive-compulsive symptoms, and prevalence of comorbid disorders did not distinguish the subgroups.

\section{Discussion}

Our study supported the contention that sensory tics are distinctive and valid symptoms of GTS, occurring more commonly than in either OCD or healthy subjects. The lifetime prevalence of $28 \%$ in our study was greater than the figure of $8.5 \%$ reported by Shapiro et $a l,{ }^{10}$ comparable with the $41 \%$ of Kurlan et $a l,{ }^{11}$ and much less than the $82 \%$ and $93 \%$ suggested by Cohen and Leckman ${ }^{12}$ and Leckman et $a l^{13}$ respectively. Shapiro and colleagues acknowledged that their figure was likely to be an underestimate because they had been "less sensitive to the existence of these symptoms when evaluating (their) early patients". ${ }^{10}$ The much broader definition used by Leckman's group, which incorporated the presence of an "urge" prior to a tic as a "sensory experience", may have accounted for the much higher prevalence they reported. Indeed, we included this feature in our definition of tics, so that all our patients with GTS would at some stage have had an "urge". In the introduction, we have explained our usage of the terms "sensory tics" and "urges", which we think is a clarification of a previously ambiguous territory. Our study also suggested that the patients with GTS with sensory tics were not atypical in other ways, a finding in agreement with both Shapiro et $a l^{10}$ and Cohen and Leckman. ${ }^{12}$ The more common occurrence of sensory tics in the rostral body regions is similar to what has previously been described for motor tics. ${ }^{101718}$ The behavioural response to the sensory tics was variable, being followed by either the purposive movements described by Shapiro et al, ${ }^{10}$ the more typical tics described by Kurlan et al, ${ }^{11}$ or no response at all.

It is of interest that within the OCD group, the presence of sensory tics was associated with a raised TSGS score and an increased risk of GTS. Moreover, like the sensory tics in the GTS group, the OCD group was more likely to experience sensory tics in rostral body areas. Taken together, these findings add a further dimension to the existing evidence that 
Table 4 Comparison of the subgroups with and without sensory tics within each group

\begin{tabular}{|c|c|c|c|c|c|c|}
\hline & \multicolumn{2}{|l|}{ GTS } & \multicolumn{2}{|l|}{$O C D$} & \multicolumn{2}{|l|}{ Healthy } \\
\hline & $\begin{array}{l}\text { With } \\
n=14\end{array}$ & $\begin{array}{l}\text { Without } \\
n=36\end{array}$ & $\begin{array}{l}\text { With } \\
n=5\end{array}$ & $\begin{array}{l}\text { Without } \\
n=45\end{array}$ & $\begin{array}{l}\text { With } \\
n=4\end{array}$ & $\begin{array}{l}\text { Withour } \\
n=41\end{array}$ \\
\hline Age (y, mean (SD)) & $20 \cdot 2(10 \cdot 3)$ & $21 \cdot 0(11 \cdot 1)$ & $25.8(11.9)$ & $31 \cdot 8(13 \cdot 4)$ & $21.5(3.4)$ & $20 \cdot 7(5 \cdot 4)$ \\
\hline $\operatorname{Sex} M / F(n)$ & $10 / 4$ & $30 / 6$ & $3 / 2$ & $26 / 19$ & & $20 / 21$ \\
\hline TSGS score $\nmid$ (mean (SD)) & $24 \cdot 6(10 \cdot 3)$ & $22 \cdot 4(15 \cdot 5)$ & $9 \cdot 2(12 \cdot 6)$ & $0.36(1 \cdot 2)$ & $0(0)$ & $0(0)$ \\
\hline Y-BOCS score (mean (SD)) & $5 \cdot 3(7 \cdot 8)$ & $5 \cdot 7(8 \cdot 5)$ & $17 \cdot 8(11.9)$ & $18 \cdot 3(7 \cdot 3)$ & $1 \cdot 5(3 \cdot 0)$ & $0(0)$ \\
\hline \multicolumn{7}{|l|}{ Lifetime prevalences $(\mathrm{n})$ : } \\
\hline GTS $\ddagger$ & 14 & 36 & 3 & 2 & 0 & 0 \\
\hline Chronic tic disorder & 0 & 0 & 2 & 6 & 0 & 0 \\
\hline Transient tic disorder & 0 & 0 & 0 & 0 & 1 & 1 \\
\hline OCD & 3 & 6 & 5 & 45 & 0 & 0 \\
\hline Major depression & 4 & 5 & 4 & 30 & 0 & 1 \\
\hline Mania & 1 & 0 & 0 & 4 & 0 & 0 \\
\hline
\end{tabular}

GTS = Gilles de la Tourette syndrome; OCD = obsessive-compulsive disorder; TSGS = Tourette syndrome global scale; YBOCS = Yale-Brown obsessive-compulsive scale.

fOCD with sensory tic $v$ OCD without sensory tic: Mann-Whitney $U=56.5, \mathrm{P}<0.05$ (one tailed).

$\ddagger$ OCD with sensory tic $v$ OCD without sensory tic: Fisher's exact test, odds ratio $=32 \cdot 2, \mathrm{P}<0.01$ (one tailed).

there may be a subgroup of patients with OCD that is predisposed to tics. ${ }^{35}$ It is unlikely that the patients with OCD with sensory tics were, in fact, misassigned patients with GTS. Table 4 shows that the obsessive-compulsive symptoms of the subgroup of patients with OCD and sensory tics were as severe as those without sensory tics, and their tics were in general much milder than the patients with GTS (TSGS scores: $t=1 \cdot 9$, df $=53, \mathrm{P}<$ 0.05 , one tailed).

A possible criticism of our study is the difference in age and sex ratios between the groups. We do not think that this compromises the results, as there was no evidence from our examination of subgroups with and without sensory tics that age or sex were significant determinants of prevalence. Further, the published evidence does not point to any such relation. ${ }^{1012}$ Our sample highlights the difficulties in recruiting young patients with OCD and female patients with GTS in adult neuropsychiatric units.

The medical literature on the neuroanatomy of GTS has speculated on the role of the basal ganglia and its connections to the frontal lobe and limbic system. ${ }^{1920}$ In particular, the basal ganglia, thalamus and primary motor, orbitofrontal, prefrontal and anterior cingulate cortices have been implicated, largely on the basis of a few studies using functional $^{21-23}$ and structural imaging. ${ }^{24}$ The neurobiology of sensory phenomena preceding movements or vocalisations may further our understanding of the neuroanatomy of GTS. When Penfield and Welch ${ }^{26}$ investigated the supplementary motor area, they reported that movements, vocalisations, and somatosensory experiences could be elicited by electrical stimulation of this area. Subsequent authors have also noted that somatic sensations were produced when this area was stimulated. ${ }^{27}{ }^{28}$ In addition, Fried et $a^{28}$ showed that whereas low stimulation currents could result in sensory experiences,-urges to move or somatic sensations such as tingling or numbness-increasing the currents gave rise to movements or vocalisations at, or proximal to, the point where the sensations were experienced. The resulting movements could either be simple movements localised to a single body part, or complex movements involving more than one body part. The supplementary motor area is rich in connections to both the frontal cortex and the basal ganglia, areas which have previously been implicated in GTS, and seems to play a key part in the internal generation of movement. ${ }^{29-32}$ The parallels between the symptoms of GTS and those produced by experimental stimulation of the suppementary motor area are striking, and raise the possibility that this area forms part of the pathway mediating tics and their precursors. A plausible neurophysiological model for sensory tics and premonitory urges is that they represent the subjectively experienced components of subthreshold disturbances in the neurological pathways mediating motor and vocal tics. Whether motor or vocal tics are associated with sensory tics would depend on the further progression of this disturbance. Motor responses which consist of more complex, purposive movements may either be voluntary movements in response to the discomfort caused by sensory tics or "involuntary" complex tics. Further research using PET, or neurophysiological techniques such as the study of movement related potentials, may help to elucidate the role of the supplementary motor area in the production of tics.

We conclude that sensory tics are intrinsically linked to other tic symptoms and are a common feature of GTS. They also occur in a subpopulation of patients with OCD who have an associated increased prevalence of GTS. Neurophysiologically, sensory tics may reflect dysfunction in the supplementary motor area or related brain regions below the threshold for the production of motor or vocal tics.

We thank Dr David Pauls for the interview schedule, Drs Chris Wever and Joan Haliburn, the NSW Branch of the Tourette Syndrome Association, and members of the OCD Suppor Groups for their valuable assistance. This study was supported by a NSW Institute of Psychiatry Research Fellowship to K-Y C.

\section{Appendix 1: Sensory tic questions}

Probe: I would like to ask you next about whether you experience (or have experienced in the past) any bodily sensations, perhaps an itch or tingle but not limited only to these sensations, repeatedly in certain parts of the body. Most people would experience an itch in one part of the body on one day, or a tickle on another part of the body on another day, which they may respond to by scratching, and which then resolves without returning to that part of their body. This is NOT what I am referring to in the following questions. Rather, I am interested in sensations which recur so frequently in certain specific body parts that a clear pattern is obvious to you. 
Q Have you ever had such recurrent sensations? Instruction: For those who say that they have had such experiences, ask the following questions:

$\mathrm{Q}$ Can you describe to me, in your own terms, the sensation (or each of the sensations) as accurately as you can?

Q Can you tell me where the sensation (or each of the sensations) is experienced? (if appropriate, ask interviewee to point to exact site)

$Q$ Was there any evidence of injury/disease in that region (those regions) of the body at the time that sensation (those sensations) was experienced, for example, inflammation, bruising, deformity or swelling?

Q Was there any history of injury/disease in that region (those regions) of the body?

$Q$ When you experienced these sensations, would you typically respond to it in any way, for instance, do something to relieve the sensation? If so, could you describe your response as accurately as you can.

$Q$ If the subject has been diagnosed as having motor or vocal tics in a previous section of the interview, ask the following question: Were any of the motor or vocal tics that you told me about earlier (give some examples) typically preceded by these sensations?

1 American Psychiatric Association. DSM-IV, diagnostic and statistical manual for mental disorders. 4th ed. Washington DC: APA, 1994

2 Frankel M, Cummings JL, Robertson MM, et al. Obsessions and compulsions in Gilles de la Tourette syndrome. Neurology 1986;36:378-382.

3 Pitman RK, Green RC, Jenike MA, et al. Clinical comparison of Tourette's disorder and obsessive-compulsive disson of Tourette's disorder and obsessive-com

4 Grad LR, Pelcovitz D, Olson M, et al. Obsessive-compulsive symptomatology in children with Tourette's sive symptomatology in children with Tourette's
Syndrome. $\mathcal{A}$ Amer Acad Child Adol Psychiatry 1987;26:

5 Leonard HL, Lenane MC, Swedo SE, et al. Tics and Tourette's Disorder: a 2- to 7-year follow-up of 54 obsessive-compulsive children. Am $\mathcal{f}$ Psychiatry 1992;149: 1244-50.

6 Robertson MM, Channon S, Baker J, et al. The psychopathology of Gilles de la Tourette's syndrome. A controlled study. BrF Psychiatry 1993;62:114-7.

7 Apter A, Pauls DL, Bleich A, et al. An epidemiologic study of Gilles de la Tourette's syndrome in Israel. Arch Gen Psychiatry 1993;50:734-8.

8 Pauls DL, Towlin KE, Leckman JF, et al. Gilles de la Tourette syndrome and obsessive-compulsive disorder: evidence supporting a genetic relationship. Arch Gen Psychiatry 1986;43:1180-2.

9 Bliss J, Cohen DJ, Freedman DX. Sensory experiences of Gilles de la Tourette syndrome. Arch Gen Psychiatry
(a) J 1980;37:1343-7.

10 Shapiro AK, Shapiro ES, Young JG, et al. Gilles de la Tourette syndrome. New York: Raven Press, 1988

11 Kurlan R, Lichter D, Hewitt D. Sensory tics in Tourette's syndrome. Neurology 1989;39:731-4.

12 Cohen A, Leckman JF. Sensory phenomena associated with Gilles de la Tourette's syndrome. f Clin Psychiatry 1992;53:319-23.

13 Leckman JF, Walker DE, Cohen DJ. Premonitory urges in Tourette's Syndrome. Am f Psychiatry 1993;150:98-102.

14 Harcherik DF, Leckman JF, Detlor J. A new instrument for clinical studies of Tourette's syndrome. $\mathcal{F}$ Am Acad Child Psychiatry 1984;23:153-60.

15 Goodman WK, Price LH, Rasmussen SA, et al. The YaleBrown obsessive-compulsive scale, I: development, use Brown obsessive-compulsive scale, I: development,
and reliability. Arch Gen Psychiatry 1989;46:1006-11.

16 Goodman WK, Price LH, Rasmussen SA, et al. The YaleBrown obsessive-compulsive scale, II: validity. Arch Gen Psychiatry 1989;46:1012-6.

17 Lees AJ, Robertson M, Trimble MR, et al. A clinical study of Gilles de la Tourette syndrome in the United Kingdom. $f$ Neurol Neurosurg Psychiatry 1984;47:1-8.

18 Nomura Y, Segawa M. Tourette syndrome in oriental children: clinical and pathophysiological considerations. In: Friedhoff A, Chase TN, eds. Gilles de la Tourette syndrome, advances in neurology. Vol 35. New York: Raven Press, 1982.

19 Cummings JL, Frankel M. Gilles de la Tourette syndrome and the neurological basis of obsessions and compulsions. Biol Psychiatry 1985;20:1117-26.

20 Haber SN, Lynd-Balta E. Basal ganglia-limbic system interactions. In: Kurlan R, Ed. Handbook of Tourette's syndrome and related tic and behavioural disorders. New syndrome and related tic and behat

21 Chase TN, Geoffrey V, Gillespie M, et al. Structural and functional studies of Gilles de la Tourette Syndrome. Rev Neurol (Paris) 1986;142:851-5.

22 George MS, Trimble MR, Costa DC. Elevated frontal cerebral blood flow in Gilles de la Tourette syndrome: a 99Tcm-HMPAO SPECT study. Psychiatry Research: Neuroimaging 1992;45:143-51.

23 Stoetter B, Braun A, Randolph C, et al. Functional neuroanatomy of Tourette syndrome. Limbic-motor interactions studies with FDG-PET. In: Chase TN, Friedhoff AJ, Cohen DJ, eds. Advances in neurology. Vol 58. New York: Raven Press, 1992.

24 Singer HS, Reiss AL, Brown JE, et al. Volumetric MRI changes in basal ganglia of children with Tourette's synchanges in basal ganglia of childre
drome. Neurology 1993;43:950-6.

25 Peterson B, Riddle MA, Cohen DJ, et al. Reduced basal ganglia volumes in Tourette's syndrome using threedimensional reconstruction techniques from magnetic resonance images. Neurology 1993;43:941-9.

26 Penfield W, Welch $\mathrm{K}$. The supplementary motor area of the cerebral cortex. A clinical and experimental study. Arch Neurol Psychiatry 1951;66:289-317.

27 Van Buren JM, Fedio P. Functional representation on the medial aspect of the frontal lobes in man. $\mathcal{F}$ Neurosurg 1976;44:275-89.

28 Fried I, Katz A, McCarthy G, et al. Functional organization of human supplementary motor cortex studied by electrical stimulation. $\mathcal{F}$ Neurosci 1991;11:3656-66.

29 Hoover JE, Strick PL. Multiple output channels in the basal ganglia. Science 1993;259:819-21.

30 Schultz W, Romo R. Role of primate basal ganglia and frontal cortex in the internal generation of movements I. Preparatory activity in the anterior striatum. Exp Brain Res 1992;91:363-84.

31 Romo R, Scarnati E, Schultz W. Role of primate basal ganglia and frontal cortex in the internal generation of movements II. Movement related activity in the anterior striatum. Exp Brain Res 1992;91:385-95.

32 Romo R, Schultz W. Role of primate basal ganglia and frontal cortex in the internal generation of movements III. Neuronal activity in the supplementary motor area. Exp Brain Res 1992;91:396-407. 